\title{
Inelastic electron tunneling spectroscopy of phenol and hydroquinone chemisorbed on alumina
}

\author{
B. F. Lewis, W. M. Bowser, J. L. Horn Jr., T. Luu, and W. H. Weinberg \\ Division of Chemistry and Chemical Engineering, and Jet Propulsion Laboratory, California Institute of \\ Technology, Pasadena, California 91103 \\ (Received 13 August 1973)

\begin{abstract}
Inelastic electron tunneling spectroscopy has been used to probe the irreversible chemisorption of $\mathrm{C}_{6} \mathrm{H}_{5} \mathrm{OH}$ and 1,4- $\mathrm{C}_{6} \mathrm{H}_{4}(\mathrm{OH})_{2}$ on a thin amorphous film of $\mathrm{Al}_{2} \mathrm{O}_{3}$. This spectroscopy yields a representation of the vibronic excitations of the chemical bonds in the adspecies, i.e., the tunneling spectra are analogous to ir spectra. The $\mathrm{C}_{6} \mathrm{H}_{5} \mathrm{OH}$ is found to adsorb predominately as $\mathrm{C}_{6} \mathrm{H}_{5} \mathrm{O}^{-}$with a small amount of adsorption as $\mathrm{C}_{6} \mathrm{H}_{5} \mathrm{OH}$. The $1,4-\mathrm{C}_{6} \mathrm{H}_{4}(\mathrm{OH})_{2}$ is found to adsorb predominately as $\mathrm{C}_{6} \mathrm{H}_{4}(\mathrm{OH}) \mathrm{O}^{-}$and perhaps to a smaller extent as $\mathrm{C}_{6} \mathrm{H}_{4} \mathrm{O}_{2}^{2-}$. Extensive hydrogen bonding is observed among adsorbates and between adsorbates and the hydroxylated alumina surface.
\end{abstract}

\section{INTRODUCTION}

The irreversible chemisorption of phenol, $\mathrm{C}_{6} \mathrm{H}_{5} \mathrm{OH}$, and hydroquinone, 1,4- $\mathrm{C}_{6} \mathrm{H}_{4}(\mathrm{OH})_{2}$, on amorphous alumina has been investigated using inelastic electron tunneling spectroscopy. The inelastic electron tunneling phenomena which will be discussed involve the tunneling of electrons through an insulating oxide barrier between two metal electrodes and the interaction of these electrons with adsorbates at the oxide-metal interface.

In pioneering work, Lambe and Jaklevic ${ }^{1,2}$ have shown that the second derivative of the characteristic currentvoltage $(I-V)$ function of a tunneling junction is analogous to an ir absorption spectrum. In the case of molecular adsorbates on the insulator surface of tunneling junctions, the molecular symmetry is ordinarily broken so that both Raman and ir vibrational modes are observed. Thus inelastic tunneling spectroscopy is a potentially powerful experimental probe of the chemical interaction of molecules adsorbed on insulating surfaces.

In the present work, inelastic tunneling spectra of phenol and hydroquinone have been measured and compared to Raman and ir spectroscopy for the same adsorbate-adsorbent systems.

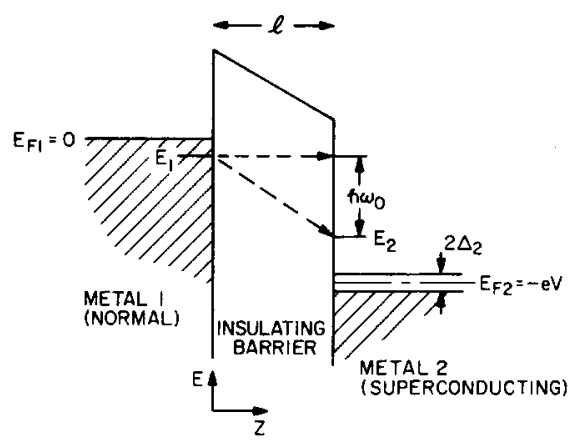

FIG. 1. Schematic diagram for the inelastic electron tunneling between energy level $E_{1}$ in a normal metal and energy level $E_{2}$ in a superconducting metal of energy gap $2 \Delta_{2}$. The Fermi level of the normal metal is $E_{F 1}=0$, while that of the superconducting metal is $E_{F 2}=-e V$ where $e V$ is the applied bias voltage. Elastic tunneling is represented by the horizontal dashed line, while inelastic tunneling is represented by the oblique dashed line resulting in a vibronic excitation of energy $\hbar \omega_{0}$. The width of the insulating barrier is given by $l$.

\section{THEORY}

The theory of inelastic tunneling spectroscopy has been discussed in detail previously $y^{-5}$ and will be very briefly reviewed here as it applies to the metal-metal oxide-superconductor junctions used in the present work. Vibronic excitations can occur within the adsorbed molecules present at the oxide insulator surface if $e V \geq \hbar \omega_{0}+\Delta_{2}$, where $e V$ is the bias voltage applied across the vibrational excitation in the adsorbate, and $2 \Delta_{2}$ is the energy gap of the superconductor. The tunneling spectra are measured at temperatures low enough $(4.2 \mathrm{~K})$ to insure that all vibrational modes of the adsorbate are in their ground states. An energy diagram describing this physical situation is shown in Fig. 1. Horizontal transitions from energy level $E_{1}$ of metal 1 correspond to elastic tunneling, whereas inelastic transitions correspond to an energy loss of $\hbar \omega_{0}$.

It has been shown that the derivative of the junction conductance, $d^{2} I / d V^{2}$, is analogous to the ir absorption spectrum of the adsorbate. ${ }^{2}$ Thus, inelastic electron tunneling spectroscopy may be used to study chemisorption and heterogeneously catalyzed surface reactions in much the same way absorption ir spectroscopy has been employed previously. The $d^{2} I / d V^{2}$ peak intensities are proportional to the surface coverage; and the observed peaks and peak positions reveal which bonds are broken and formed during chemisorption and/or surface reaction. Shifts in peak positions give information about both adsorbate-adsorbent and adsorbate-adsorbate interactions.

\section{EXPERIMENTAL}

The tunneling junctions were made by the techniques developed by Lambe and Jaklevic ${ }^{1,2}$ and Geiger et al. ${ }^{6}$ Briefly, this consists of evaporating an $\mathrm{Al}$ strip onto a glass slide and then oxidizing the surface of the strip in a glow discharge of pure oxygen. After evacuating the oxygen from the high vacuum system, the oxidized $\mathrm{Al}_{2} \mathrm{O}_{3}$ strip is exposed to approximately 6 Torr $\cdot \sec$ of the desired adsorbate. The adsorbate vapor is then evacuated, and a $\mathrm{Pb}$ cross strip is evaporated onto 
the oxidized strip. These steps are all conducted in a chamber whose base pressure is on the order of $10^{-6}$ Torr. Immediately after the junctions are made, they are stored in liquid $\mathrm{N}_{2}$ and never again warmed up above $77 \mathrm{~K}$. All adsorption experiments are conducted at room temperature.

The tunneling spectra are obtained by measuring the second derivative of the $I-V$ characteristic of the junction. The bias current is modulated with an ultrapure $50-\mathrm{kHz}$ sine wave, and the second harmonic voltage generated across the junction is measured with a lock-in detector. The modulation voltage generated across the sample is usually $2 \mathrm{meV}$ peak-to-peak or less, and the second harmonic voltage is less than $1 \mu \mathrm{eV} \mathrm{rms.}$ During such measurements the samples are immersed in liquid $\mathrm{He}$ and can easily be cooled to $1.3 \mathrm{~K}$.

\section{CHEMISORPTION OF PHENOL AND HYDROQUINONE}

As described previously, the $\mathrm{Al}_{2} \mathrm{O}_{3}$ surfaces were given saturation (6-Torr-sec) exposures of both $\mathrm{C}_{6} \mathrm{H}_{5} \mathrm{OH}$ and $1,4-\mathrm{C}_{6} \mathrm{H}_{4}(\mathrm{OH})_{2}$ at $300 \mathrm{~K}$. The inelastic electron tunneling spectra of the $\mathrm{C}_{6} \mathrm{H}_{5} \mathrm{OH}$ and the 1,4- $\mathrm{C}_{6} \mathrm{H}_{4}(\mathrm{OH})_{2}$ are shown in Figs. 2 and 3, respectively. The various vibronic transitions in both spectra are listed in Tables I and II. Also shown in Table I are the infrared (ir) transitions in vapor, liquid, and solid $\mathrm{C}_{8} \mathrm{H}_{5} \mathrm{OH}$ and the Raman transitions of liquid $\mathrm{C}_{6} \mathrm{H}_{5} \mathrm{OH} .^{7,8}$ The ir transitions of solid and liquid $1,4-\mathrm{C}_{6} \mathrm{H}_{4}(\mathrm{OH})_{2}$ and the Raman transitions of liquid 1,4- $\mathrm{C}_{6} \mathrm{H}_{4}(\mathrm{OH})_{2}$ are shown in Table II.9 The assignments of the ir and Raman peaks are also given in both Tables I and II.

From the spectrum shown in Fig. 2, it is concluded that most of the $\mathrm{C}_{6} \mathrm{H}_{5} \mathrm{OH}$ chemisorbs on $\mathrm{Al}_{2} \mathrm{O}_{3}$ as a phenoxide ion by cleaving the $\mathrm{OH}$ bond in the adsorbate. In tunneling junctions made with no intentionally introduced adsorbate, the oxide surface is saturated with $\mathrm{OH}$ groups ${ }^{2,6,10,11}$ and the tunneling spectra show $\mathrm{OH}$ stretching vibrations (ca. $448 \mathrm{meV}$ ) very similar in intensity and shape to those observed for $\mathrm{C}_{6} \mathrm{H}_{6} \mathrm{OH}$ junctions. Thus the $\mathrm{C}_{6} \mathrm{H}_{5} \mathrm{OH}$ must either displace the "clean" surface $\mathrm{OH}$ groups, adsorb with its $\mathrm{OH}$ group

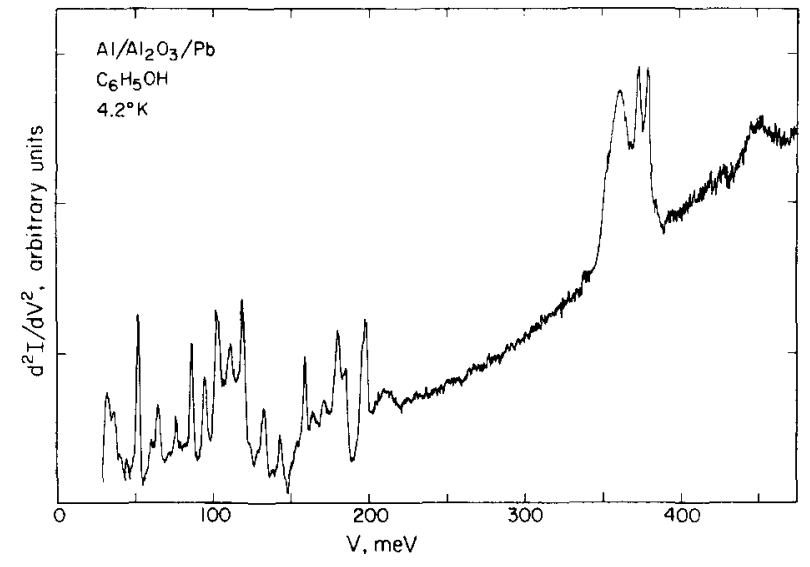

FIG. 2. Inelastic electron tunneling spectrum of $\mathrm{C}_{6} \mathrm{H}_{5} \mathrm{OH}$ adsorbed on $\mathrm{Al}_{2} \mathrm{O}_{3}$ in an $\mathrm{Al} / \mathrm{Al}_{2} \mathrm{O}_{3} / \mathrm{Pb}$ junction. $T=4.2 \mathrm{~K}$; junction impedance $=82 \Omega$; modulation voltage $=2 \mathrm{meV}$ peak-to-peak; oscillator frequency $=46 \mathrm{kHz}$.

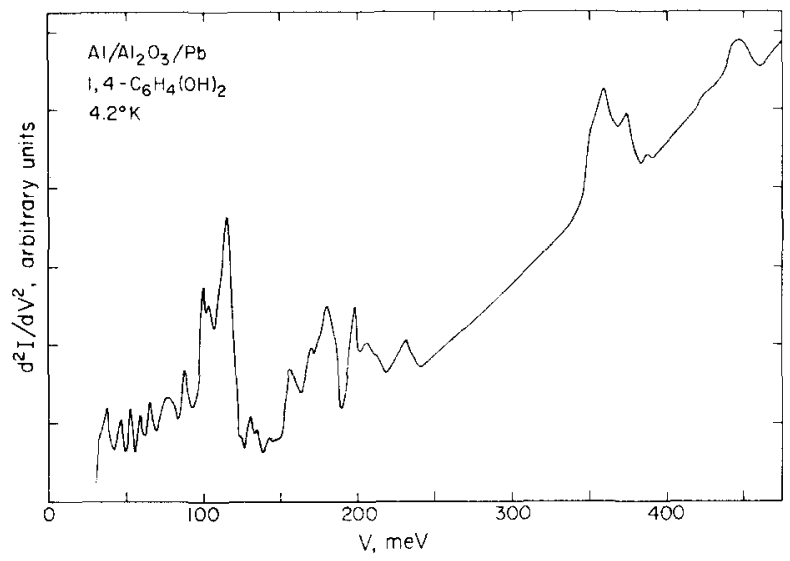

FIG. 3. Inelastic electron tunneling spectrum of $1,4-\mathrm{C}_{6} \mathrm{H}_{4}(\mathrm{OH})_{2}$ adsorbed on $\mathrm{Al}_{2} \mathrm{O}_{3}$ in an $\mathrm{Al} / \mathrm{Al}_{2} \mathrm{O}_{3} / \mathrm{Pb}$ junction. $T=4.2 \mathrm{~K}$; junction impedance $=36 \Omega$; modulation voltage $=2 \mathrm{meV}$ peak-to-peak; oscillator frequency $=47 \mathrm{kHz}$.

orthogonal to the electric field of the tunneling electrons, or adsorb predominately as a phenoxide ion. In either of the first two cases, the ring stretch with $\mathrm{OH}$-bendingcharacter vibrations at 170.9 and $163.3 \mathrm{meV}$ would be much stronger than is observed. The second case is also unlikely since the oxide is amorphous. There must be a distribution of adsorbate orientations on the surface. Thus most of the $\mathrm{C}_{6} \mathrm{H}_{5} \mathrm{OH}$ chemisorbs as a phenoxide ion. However, a small amount of $\mathrm{C}_{6} \mathrm{H}_{5} \mathrm{OH}$ evidently chemisorbs on the $\mathrm{Al}_{2} \mathrm{O}_{3}$ associatively as judged by the weak peaks at $418.8,170.9$, and $163.3 \mathrm{meV}$. That is, there is a small amount of irreversibly adsorbed molecular $\mathrm{C}_{6} \mathrm{H}_{5} \mathrm{OH}$ on the $\mathrm{Al}_{2} \mathrm{O}_{3}$ after evacuation of the adsorbate from the gas phase at $300 \mathrm{~K}$ to a partial pressure $<10^{-5}$ Torr. The strong transition in adsorbed $\mathrm{C}_{6} \mathrm{H}_{5} \mathrm{OH}$ present at $118.5 \mathrm{meV}$ is due not only to a $\mathrm{CH}$ bending mode of the adsorbate, but also to an $\mathrm{Al}-\mathrm{O}$ stretching mode in the adsorbent., ${ }^{2,6,10,11}$ All of the other transitions are indicative of an adsorbed phenoxide ion chemisorbed to the $\mathrm{Al}^{3+}$ site of the $\mathrm{Al}_{2} \mathrm{O}_{3}$ surface.

It is also clear from Fig. 2 that there is a considerable amount of hydrogen bonding between the adsorbed $\mathrm{C}_{6} \mathrm{H}_{5} \mathrm{O}^{-}$and presumably adjacent $\mathrm{OH}$ groups on the $\mathrm{Al}_{2} \mathrm{O}_{3}$ surface; this is apparent from the long asymmetric tailing of the $\mathrm{OH}$ stretching mode to lower energies. Such a tail is present on the "clean" hy. droxylated surface, but is smaller, i.e., there is only a relatively small amount of hydrogen bonding between the $\mathrm{OH}$ groups on the otherwise clean $\mathrm{Al}_{2} \mathrm{O}_{3}$ surface. It should also be noted that Raman modes are evidently active in adsorbed $\mathrm{C}_{6} \mathrm{H}_{5} \mathrm{O}^{-}$due both to the high intensity of the $\mathrm{CH}$ stretching modes and the presence of the 124.4-meV "ring breathing" mode.

The extremely high resolution of IETS is obvious from Fig. 2 and even more apparent when compared with a recent investigation of $\mathrm{C}_{8} \mathrm{H}_{5} \mathrm{OH}$ chemisorption on $\mathrm{Al}_{2} \mathrm{O}_{3}$ using absorption ir spectroscopy. ${ }^{12}$ The ir results also indicate that $\mathrm{C}_{6} \mathrm{H}_{5} \mathrm{OH}$ is chemisorbed as a phenoxide ion on $\mathrm{Al}_{2} \mathrm{O}_{3}$ at $425 \mathrm{~K}$, but only five transitions are resolved above $150 \mathrm{meV}-\mathrm{CH}$ stretching modes at 378 and $374 \mathrm{meV}$, aromatic ring vibrations at 199 and 185 
TABLE 1. Infrared and Raman transitions in phenol and inelastic electron tunneling transitions in phenol adsorbed on an alumina film."

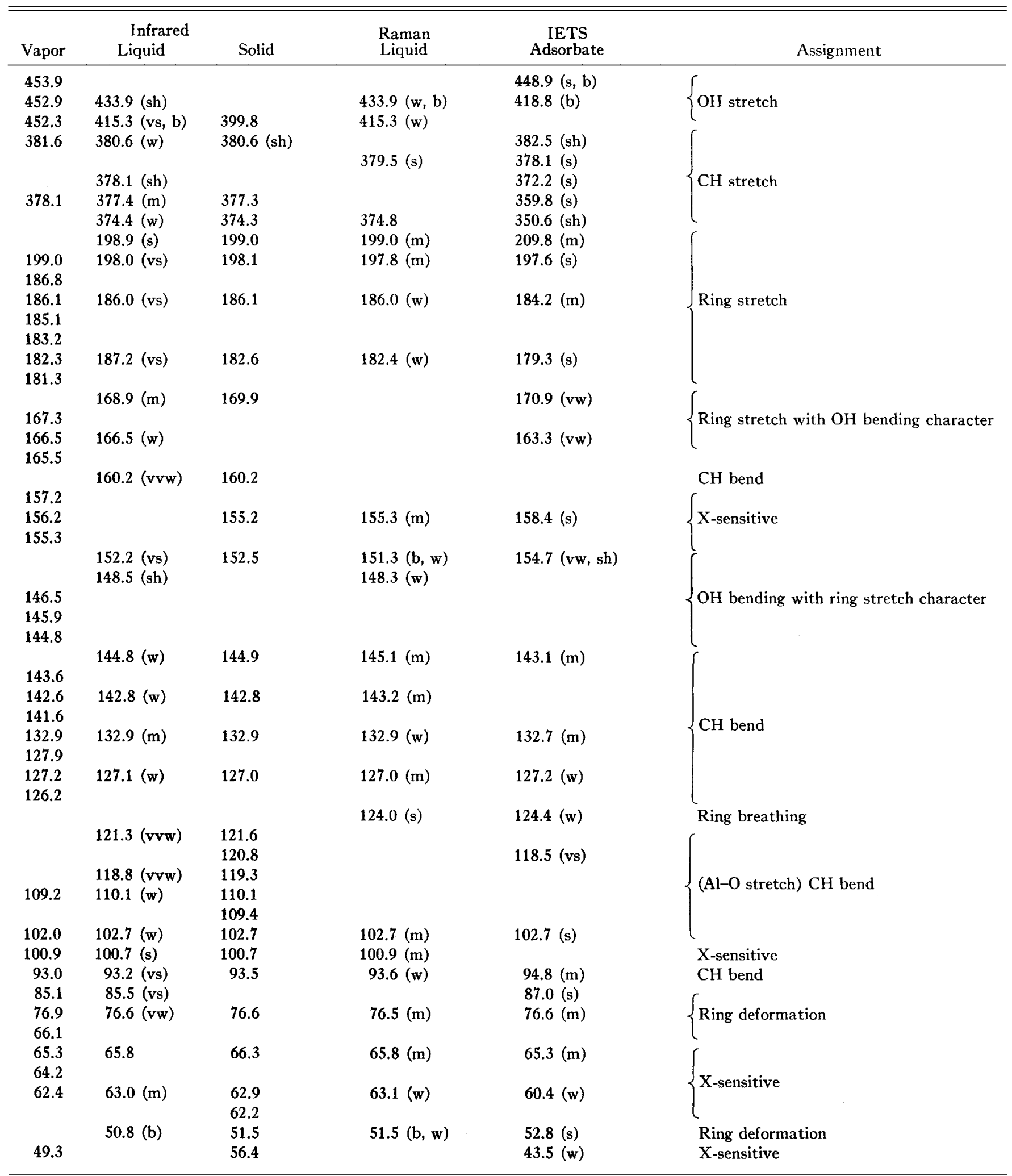

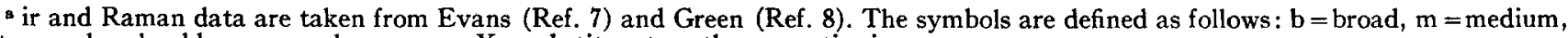
$\mathrm{s}=$ strong, $\mathrm{sh}=$ shoulder, $\mathrm{w}=$ weak, $\mathrm{v}=$ very, $\mathrm{X}=$ substituent on the aromatic ring.

$\mathrm{MeV}$, and a $\mathrm{CO}$ stretching mode (i.e., an $x$-sensitive mode) at $159 \mathrm{meV} .^{9}$ This is in good agreement with the present results, but the much higher resolution of IETS should be emphasized.

The inelastic electron tunneling spectrum of adsorbed $1,4-\mathrm{C}_{6} \mathrm{H}_{4}(\mathrm{OH})_{2}$ is shown in Fig. 3, and the results are similar to those of $\mathrm{C}_{6} \mathrm{H}_{5} \mathrm{OH}$. The higher intensity of the $448.1-\mathrm{meV} \mathrm{OH}$ stretching mode and its attendant lowenergy tail and broad peak at $425.0 \mathrm{meV}$ suggest that one of the $\mathrm{OH}$ bonds is preserved in adsorbed 1,4$\mathrm{C}_{6} \mathrm{H}_{4}(\mathrm{OH})_{2}$, and the adsorption occurs by cleaving the other $\mathrm{OH}$ bond analogous to the mode of adsorption of 
TABLE II. Infrared and Raman transitions in hydroquinone and inelastic electron tunneling transitions in hydroquinone adsorbed on an alumina film. ${ }^{\mathrm{a}}$

\begin{tabular}{|c|c|c|c|c|}
\hline \multicolumn{2}{|c|}{ Infrared } & \multirow{2}{*}{$\begin{array}{l}\text { Raman } \\
\text { Liquid }\end{array}$} & \multirow{2}{*}{$\begin{array}{c}\text { IETS } \\
\text { Adsorbate }\end{array}$} & \multirow[b]{2}{*}{ Assignment } \\
\hline Solid & Liquid & & & \\
\hline & & & $\begin{array}{l}448.1(\mathrm{~s}, \mathrm{~b}) \\
425.0(\mathrm{w}, \mathrm{b})\end{array}$ & $\mathrm{OH}$ stretch \\
\hline $\begin{array}{l}406.4 \\
375.7\end{array}$ & $\begin{array}{l}420.8 \\
375.2\end{array}$ & & $\begin{array}{l}425.0(w, b) \\
388.1(w)\end{array}$ & \\
\hline 364.4 & 367.1 & & $375.6(\mathrm{~m})$ & \\
\hline 363.5 & 357.3 & & $360.3(\mathrm{~s})$ & CH stretch \\
\hline 353.6 & 350.6 & & $352.5(\mathrm{sh})$ & \\
\hline 337.5 & 337.5 & & $337.5(\mathrm{sh})$ & \\
\hline 230.2 & 230.2 & & $231.9(w)$ & \\
\hline 226.9 & 226.9 & & $207.5(w)$ & \\
\hline 201.6 & 202.1 & 199.7 & $197.5(\mathrm{~m})$ & Ring stretch \\
\hline 187.5 & 187.5 & & $186.2(\mathrm{sh})$ & \\
\hline 181.9 & 180.4 & & $181.2(\mathrm{~m})$ & \\
\hline 166.4 & 165.5 & & $170.0(\mathrm{sh})$ & $\mathrm{OH}$ bend \\
\hline 161.8 & 163.3 & & & $\mathrm{CH}$ bend \\
\hline 155.0 & 154.4 & 156.7 & $156.8(\mathrm{~m})$ & \\
\hline 153.1 & 152.1 & 153.2 & & $\mathrm{OH}$ bend \\
\hline 149.2 & 149.6 & & & \\
\hline 147.3 & 148.2 & & & \\
\hline 144.1 & 144.1 & 143.6 & $143.1(w)$ & \\
\hline 138.4 & 138.2 & & $135.0(\mathrm{sh})$ & \\
\hline 136.0 & 136.4 & & $131.2(\mathrm{~m})$ & \\
\hline 125.2 & 125.3 & & $123.8(\mathrm{sh})$ & \\
\hline 116.5 & 116.2 & & $115.6(\mathrm{vs})$ & $\mathrm{CH}$ bena \\
\hline 114.1 & 113.9 & & & \\
\hline 110.3 & 111.3 & & & \\
\hline 102.8 & 103.2 & 105.8 & $105.0(\mathrm{~m})$ & \\
\hline 100.4 & 98.9 & 102.8 & $100.8(\mathrm{~m})$ & \\
\hline \multirow[t]{2}{*}{94.2} & 94.5 & & $97.2(\mathrm{sh})$ & Ring deformation \\
\hline & 93.2 & & $89.0(\mathrm{~m})$ & $\mathrm{CH}$ bend \\
\hline 84.2 & 83.9 & & 86.0 (sh) & \\
\hline 75.5 & 75.6 & 80.7 & $80.4(w)$ & \\
\hline 67.6 & 67.4 & & $72.0(\mathrm{w})$ & \\
\hline 64.3 & 64.1 & 65.8 & $66.8(w)$ & Ring deformation \\
\hline \multirow[t]{3}{*}{56.9} & 56.8 & 58.0 & $59.8(\mathrm{~m})$ & \\
\hline & 51.1 & & $53.2(\mathrm{~m})$ & \\
\hline & 47.7 & & $47.1(\mathrm{~m})$ & \\
\hline
\end{tabular}

ir and Raman data taken from Hidalgo and Otero (Ref. 9). Symbols are defined in Table $I$.

$\mathrm{C}_{6} \mathrm{H}_{5} \mathrm{OH}$ (e.g., compare the intensity of the $\mathrm{OH}$ stretching to $\mathrm{CH}$ stretching modes in $1,4-\mathrm{C}_{6} \mathrm{H}_{4}(\mathrm{OH})_{2}$ to those in $\left.\mathrm{C}_{6} \mathrm{H}_{6} \mathrm{OH}\right)$. The possibility of adsorption without cleaving either $\mathrm{OH}$ bond cannot be ruled out entirely. Analysis of the data is not yet sufficiently refined to determine whether the $\mathrm{OH}$ bending vibrations observed at 170.0 and $156.9 \mathrm{meV}$ are indicative of one or two $\mathrm{OH}$ groups per adsorbed molecule. Indeed, there may be di-adsorbed ions (cleaving both $\mathrm{OH}$ bonds), especially at low surface coverage. In view of the results for $\mathrm{C}_{6} \mathrm{H}_{5} \mathrm{OH}$, however, it is most probable that adsorption occurs predominately by cleaving one of the $\mathrm{OH}$ bonds.

There is a considerable amount of hydrogen bonding apparent for the adsorbed $1,4-\mathrm{C}_{6} \mathrm{H}_{4}(\mathrm{OH})_{2}$, even more than in the case of adsorbed $\mathrm{C}_{6} \mathrm{H}_{5} \mathrm{OH}$. This is to be expected in view of the additional $\mathrm{OH}$ group present in 1,4- $\mathrm{C}_{6} \mathrm{H}_{4}(\mathrm{OH})_{2}$. As noted above for the case of $\mathrm{C}_{6} \mathrm{H}_{5} \mathrm{OH}$, the transition at 448.1 and $115.6 \mathrm{meV}$ in Fig. 3 and Table II are indicative to some extent of the $\mathrm{Al}_{2} \mathrm{O}_{3}$ adsorbent in the absence of any adsorbate.

\section{SUMMARY}

Inelastic electron tunneling spectroscopy has been used to probe the chemisorption of phenol and hydroquinone on the surface of an $\mathrm{Al}_{2} \mathrm{O}_{3}$ film in an $\mathrm{Al} /$ $\mathrm{Al}_{2} \mathrm{O}_{3} / \mathrm{Pb}$ tunnel junction. The measurement temperature was $4.2 \mathrm{~K}$, and thus the junction was of the type $\mathrm{NS}$ with normal $\mathrm{Al}$ and superconducting $\mathrm{Pb}$.

Both $\mathrm{C}_{6} \mathrm{H}_{5} \mathrm{OH}$ and 1,4- $\mathrm{C}_{6} \mathrm{H}_{4}(\mathrm{OH})_{2}$ chemisorb irreversibly on the $\mathrm{Al}^{3+}$ sites of the $\mathrm{Al}_{2} \mathrm{O}_{3}$ surface at room temperature. The $\mathrm{C}_{6} \mathrm{H}_{5} \mathrm{OH}$ adsorbs predominantly as a $\mathrm{C}_{6} \mathrm{H}_{5} \mathrm{O}^{-}$, and the $1,4-\mathrm{C}_{6} \mathrm{H}_{4}(\mathrm{OH})_{2}$ predominantly as a $\mathrm{C}_{6} \mathrm{H}_{4}(\mathrm{OH}) \mathrm{O}^{-}$. There is also a small fraction of the $\mathrm{Al}_{2} \mathrm{O}_{3}$ which chemisorbs associated $\mathrm{C}_{6} \mathrm{H}_{5} \mathrm{OH}$ at a room temperature exposure of 6 Torr $\cdot \mathrm{sec}$. The 1,4- $\mathrm{C}_{6} \mathrm{H}_{4}(\mathrm{OH})_{2}$ may adsorb to a very small extent both in the associated form and also as the di-ion $\mathrm{C}_{6} \mathrm{H}_{4} \mathrm{O}_{2}{ }^{2-}$. There is extensive hydrogen bonding between both the adsorbates, and the adsorbate and the $\mathrm{OH}$ groups present on the $\mathrm{Al}_{2} \mathrm{O}_{3}$ surface as witnessed by the long low-energy tail observed on the $\mathrm{OH}$ stretching mode. This occurs for both chemisorbed phenol and hydroquinone to a much greater extent than the hydrogen bonding which exists between the $\mathrm{OH}$ groups on the clean, but hydroxylated, $\mathrm{Al}_{2} \mathrm{O}_{3}$ surface. The high resolution of inelastic electron tunneling spectroscopy is especially evident when compared with adsorption ir data for $\mathrm{C}_{6} \mathrm{H}_{5} \mathrm{OH}$ adsorbed on $\mathrm{Al}_{2} \mathrm{O}_{3}{ }^{12}$

\section{ACKNOWLEDGMENTS}

The support of this research by the President's Fund of the California Institute of Technology (Grant No. PF-047) is gratefully acknowledged. We have benefited from the facilities of the Jet Propulsion Laboratory of the California Institute of Technology. JLH and TL wish to thank the Esso Corporation for partial support as participants in the undergraduate research program in the Division of Chemistry and Chemical Engineering at the California Institute of Technology.

${ }^{1}$ R. C. Jaklevic and J. Lambe, Phys. Rev. Lett. 17, 1139 (1966).

${ }^{2}$ J. Lambe and R. C. Jaklevic, Phys. Rev. 165, 821 (1968).

${ }^{3}$ D. J. Scalapino and S. M. Marcus, Phys. Rev. Lett. 18, 459 (1967).

${ }^{4}$ C. B. Duke, Tunneling in Solids (Academic, New York, 1969).

5 Tunneling Phenomena in Solids, edited by $\mathrm{E}$. Burstein and $\mathrm{S}$.

Lundquist (Plenum, New York, 1969)

6 A. L. Geiger, B. S. Chandrasekhar, and J. G. Adler, Phys. Rev. 188,1130 (1969).

7 J. C. Evans, Spectrochim. Acta 16, 1382 (1960).

8 J. H. S. Green, J. Chem. Soc. 1961, 2236.

$\checkmark$ A. Hidalgo and C. Otero, Spectrochim. Acta 16, 528 (1960).

$10 \mathrm{~J}$. Klein, A. Leger, M. Belin, D. Defourneau, and M. J. L. Sangster, Phys. Rev, B7, 2336 (1973).

11 B. F. Lewis, M. Mosesman, and W. H. Weinberg, Surf. Sci. 41, 20 (1973).

12 D. R. Taylor and K. H. Ludlum, J. Phys. Chem. 76, 2882 (1972) 